\title{
STUDENT ENGAGEMENT IN A FULLY ONLINE ACCOUNTING MODULE: AN ACTION RESEARCH STUDY
}

\author{
M. Malan \\ College of Business and Economics, School of Accounting \\ University of Johannesburg \\ Johannesburg, South Africa \\ e-mail: mmalan@uj.ac.za / https://orcid.org/0000-0003-2631-1272
}

\section{ABSTRACT}

Student engagement is crucial for learning, and especially so in online learning. For a student to be a successful online learner, they need to engage with the online content, with their peers and with the educator. This article presents an accounting module of a fully online degree where engagement was purposefully integrated using an online engagement framework. Within this framework, the educator regularly interacted with the students to ensure that they were engaging with the online material and a group task was assigned where students had to collaboratively construct knowledge and display it in a video. An action research design was followed to determine the degree of engagement within the module and to improve on it for future modules. Results indicate that regular interaction did result in more students being active and ultimately successfully completing the module. Student reflections on the group task indicated that there are definite benefits in creating knowledge collaboratively although the format in which it should be presented needs to be reconsidered.

Keywords: accounting education, action research, online learning, student engagement, selfregulated learning

\section{INTRODUCTION}

In South Africa, approximately 30 per cent of school leavers obtain the national senior certificate with a bachelor pass (Africacheck 2018). Although enough space is available in the public universities in the country, several limitations exist for prospective students to enter tertiary education. These limitations include over-application for popular degrees such as Education, Business and Economics, Health and Engineering (BusinessTech 2017). Another limitation is the funding needed by a student - not only to pay for the tertiary fees, but also for accommodation, food and travel expenses. Most bursaries and scholarships only provide funding for fees, leaving the student unable to benefit from the scholarship unless they find sponsors to cover the other expenses. Online programmes have grown over the past few years as it provides students with the ability to continue working while they study towards a degree, learn from anywhere without the need to travel to classes and the flexibility within the 
programme that gives them the option to start whenever it suits them (UJ 2019).

In South Africa as well as globally there has been a significant shift in education and especially a growing recognition for online education (Karodia 2019). This shift has come in the wake of the vast technological changes seen throughout the world. Online learning has grown from the mere recording of lecturers that are placed online to electronic assessments, blended learning and ultimately a well-designed programme that runs fully online. Expectations for the future in the online learning space in South Africa include increased use of mobile technology for learning, as well as the ability of the student to make even more flexible choices through micro-learning and adaptive learning (Stark 2019).

Online learning is shaking up the traditional way of thinking about university teaching and learning and encourages educators to look at the advantages that online learning brings and try to copy that to classroom learning (Mashile and Pretorius 2003). Advantages include the ability of a student to be in control of their learning - they can pause, rewind, fast forward and replay. Online students also learn expert technical skills necessary within the digital age (Duncan, Kenworthy and McNamara 2012). Quicker support and detailed feedback can be given as it is possible to track online students better within the Learning Management System ${ }^{1}$ (LMS) (CarrChellman and Duchastel 2000). It is however necessary for online learning to create opportunities to develop connections with people, which a traditional education system caters for daily and almost automatically (Bali and Liu 2018).

For a student to be successful as an online learner, they need to participate and engage both with others and with the online elements to create knowledge and meaning by themselves and with others (Davies and Graff 2005; Duncan et al. 2012; Hrastinski 2009; Tayebinik and Puteh 2013; Wells, De Lange and Fieger 2008; Zeng and Warschauer 2015). An online learner cannot engage with the institution as much as a face-to-face learner as they are "non-traditional" students who balance work, study and family commitments (Redmond et al. 2018). The online learning environment should therefore specifically ensure that engagement occurs.

The University of Johannesburg (UJ), a traditional residential institution in South Africa, commenced with fully online degree programmes in 2017. UJ offers several Master's degrees, advanced diplomas and Bachelor degrees fully online. The BCom International Accounting undergraduate degree is one such programme. This fully online degree equips learners to become professional accountants with expert technical knowledge, the ability to work individually and in teams and the competence to learn collaboratively and independently. This is intended to stimulate the development of lifelong learning, an important skill needed by accounting students as they have to adapt to the future world of fast-changing technology, an abundance of information and constant change (Malan and Stegmann 2018; Wells et al. 2008) 
The degree consists of 24 modules with each module ${ }^{2}$ completed within a seven-week period. Each module includes several activities designed in such a way within the LMS so that the student engages with the material, their peers and with their instructors. These engagements are used to create their knowledge of the subject. The activities include reading online content or textbooks, completing quizzes and assignments, participating in discussion boards and watching videos.

\section{RESEARCH OBJECTIVE AND CONTRIBUTION}

Educators in online learning should promote a learning environment where students can form significant engagements. Redmond et al. $(2018,199)$ state that "there is much we can do to create online learning environments that enhance learning and teaching outcomes". These environments should "provide opportunities for students to engage online, and to foster connections with each other, instructors, the educational institution and industry while developing strong disciplinary knowledge and multidisciplinary skills".

Online learning at UJ is still in its early stages, and educators such as myself are discovering how to most effectively support students in their online learning journey. As the programme coordinator for the online accounting degree, I noticed in the earlier modules in the degree, that students who engaged fully with the online learning environment were successful in a particular module. The inverse was also true - less participation and less engagement led to a failed module.

In the second accounting module of the degree (of which I am also the module coordinator) I decided to redesign the module to purposefully stimulate participation and engagement. This was done specifically through regular contact with those students who were not active or engaged in the module and through a group assignment.

The objective of this study is to reflect on the repeated contact with the students and the group task from an action research perspective. The study seeks to determine whether the repeated contact encouraged students to engage more with the online learning environment and ultimately, to complete the module successfully. The perspective of students was obtained through reflective entries in an online journal while their participation within the LMS was tracked by analysing the students' activity logs. ${ }^{3}$

The contribution of this study is threefold. Firstly, it reflects on the importance of student engagement in a fully online accounting module. Student engagement, whether in a traditional face-to-face setting or in an online environment, is crucial for learning. This study explores how engagement can be purposefully created using a framework, as proposed by literature. Secondly, as the study is set within an action research framework, it could be used to enhance 
engagement in other online courses. Furthermore, the study illustrates how this method of action research could be used by other researchers in accounting education. Thirdly, it considers the importance of participation and engagement within a fully online accounting degree, and not just within an isolated online course or an isolated online activity.

The content of this article is presented as follows: in the next section, I explore the literature on online learning, the components of a successful online course and the framework in which engagement within this learning environment occurs. I then explain the action research methodology and why it was chosen for this study. After that, I follow the steps in the action research framework and describe the first cycle, through the stages of planning, acting, observing and reflection. I conclude with a discussion of the study's implications, limitations and areas for future research.

\section{LITERATURE REVIEW}

\section{Online learning}

Online learning can be defined as "formally and systematically organized teaching and learning activities in which the educator and the learners are geographically separated, using Information and Communication Technologies (ICT) to facilitate their interaction and collaboration" (Dani, Singhai and Hyde 2018, 335). In the online environment, the educator becomes the guide and facilitates the learning process, while the student is placed at the centre of the virtual classroom and must take an active role in the learning process (Fajardo 2014; Potter and Johnston 2006; Van Oordt and Mulder 2016; Wells et al. 2008).

Due to its more autonomous nature, an online course or degree requires the student to display high levels of motivation and self-regulation (Artino Jr. and Stephens 2009; Wandler and Imbriale 2017). Self-regulatory learning skills have been positively correlated with academic achievement. Students lacking this skill within an online environment may underestimate its importance and fail in their studies (Barnard et al. 2009; Zimmerman and Schunk 2001). A self-regulated learner is an engaged learner, displaying confidence in their learning and a strong involvement in the learning process (Cho, Kim and Choi 2017; Delen and Liew 2016).

The literature also indicates that a positive correlation exists between online engagement (also described as interaction or participation) and students' learning (Carver, Mukherjee and Lucio 2017; Davies and Graff 2005; Duncan et al. 2012). In their study of undergraduates, Tayebinik and Puteh (2013) found a significant relationship between students' participation in online interactions and the grade that they earned. The more time students spent in group 
discussions, student-student interactions and student-teacher interactions, the more likely they were to pass the online module. The inverse was also noted, with irregular participation leading to failure (Canal, Ghislandi and Micciolo 2015).

\section{Characteristics of a successful online course}

To develop a self-regulated and engaging environment, online educators can design their courses for optimal active learning to occur. Specifically, the following is recommended:

- Explicit structure and organisation of the course, starting with a clear description of the learning objectives, the learning resources and the activities and assignments. This must be provided in sufficient detail so that the student can proceed with the learning tasks with minimal further instructions required (Artino Jr. and Stephens 2009; Carr-Chellman and Duchastel 2000);

- Purposeful learning tasks that students need to engage in, either individually or collaboratively. These learning tasks can take on many forms, but assignments are a true and tested method. The assignments must require critical thinking and ideally, should relate to real life situations (Carr-Chellman and Duchastel 2000; Holzweiss et al. 2014);

- Scaffolding the learning content as well as the learning experience so that students are guided in the learning process. This can take the form of scaffolding time expectations, scaffolding due dates, providing rubrics for learning tasks and creating discussion areas where students can seek help (Wandler and Imbriale 2017);

- Employing a variety of technological tools to engage learners such as quizzes, multiple choice assignments, discussion boards, journal entries and videos (Holzweiss et al. 2014);

- $\quad$ Timely and specific feedback by educators on student performance within the learning tasks to refine learning, correct mistakes, motivate students and improve their future academic performance (Carr-Chellman and Duchastel 2000; Helfaya 2019; Holzweiss et al. 2014); and

- Clear communication structures for student-student interaction and student-educator dialogue to occur. This is mainly achieved through the use of online discussion boards within the LMS and through the traditional email function (Carr-Chellman and Duchastel 2000; Cho and Kim 2013).

\section{Engagement framework}

The framework for this study is based on Astin's (1984) student involvement theory. This 
theory is concerned with the processes that enable student development, maintaining that an involved student is one who partakes in learning activities, allocates considerable time and energy to studying and interacts frequently with educators and other students (Astin 1984). Over time, educational researchers combined the student involvement theory with management theories to create a conceptual framework for student engagement (Burch et al. 2015; Kahn 1990). Their proposed framework contains three components of student engagement, namely, cognitive engagement, behavioural engagement and emotional engagement.

Within the online paradigm, three types of interaction (used interchangeably with engagement) were identified by Moore (1993), namely, learner-to-learner interaction, learnerto-instructor interaction and learner-to-content interaction. After an extensive literature review, Redmond et al. (2018) expanded on these three components of student engagement and the three types of interaction and designed an online engagement framework for higher education that presents five elements which, according to the authors, are crucial for effective student engagement within an online learning environment (refer Table 1).

Table 1: Online engagement framework for higher education

\begin{tabular}{|l|l|}
\hline \multicolumn{1}{|c|}{ Type of engagement } & \multicolumn{1}{c|}{ Indicators } \\
\hline Social engagement & $\begin{array}{l}\text { Interacting socially with peers and instructors through social forums and } \\
\text { communication platforms. } \\
\text { Developing relationships and establishing trust. }\end{array}$ \\
\hline Cognitive engagement & $\begin{array}{l}\text { Activating metacognition by thinking critically, integrating ideas and justifying } \\
\text { decisions. } \\
\text { Developing deep understanding of the content. }\end{array}$ \\
\hline Behavioural engagement & $\begin{array}{l}\text { Self-regulating learning through positive conduct, participation in activities, } \\
\text { involvement in the learning task and continuous positive attitude. } \\
\text { Developing multidisciplinary skills beyond mere technical knowledge. }\end{array}$ \\
\hline Collaborative engagement & $\begin{array}{l}\text { Learning with peers through the use of group or team activities and assessment. } \\
\text { Developing personal and professional learning networks. }\end{array}$ \\
\hline Emotional engagement & $\begin{array}{l}\text { Reacting emotionally to the process of learning through attitude, enthusiasm, } \\
\text { interest, anxiety or enjoyment. } \\
\text { Managing expectations and committing to the process of learning. }\end{array}$ \\
\hline
\end{tabular}

The need for engaged students is important in all spheres of education, whether in a traditional face-to-face or online environment. Educators can provide significant guidance to frame the learning environment in such a way that students reach their educational goals. This study explores whether this can indeed be achieved in a fully online environment.

\section{METHODOLOGY}

Action research is the method used in this study to explore an online module through a firstperson inquiry (Curtis 2017). Although there are numerous definitions of action research, Cunningham $(2008,1)$ describes it as "an iterative, systematic, analytic way to reflect on what 
we are doing in class, to evaluate our success at achieving our classroom goals, and to chart the direction of future classroom strategies based on what we have learned". In recent years, action research has featured more prominently in accounting education, providing guidance to other researchers as to how it can be effectively applied (Helfaya 2019; Ingersoll Abbott and Palatnik 2018; Williams, Horner and Allen 2019). It involves cycles of planning, acting and observing, as well as critical self-reflection. Here, the researcher critiques the process, the interventions, the subsequent plans and the improved strategies (Cousin 2009; Cunningham 2008; Curtis 2017; Kember and Gow 1992; Paisey and Paisey 2005). The action research cycle can be explored in various ways, but I adopted the stepped approach as used by McGowan (2012). This involves four steps - planning, taking action, observing and reflecting to implement change.

I adopted the action research method in order to critically reflect on the Accounting 12 (Acc12) online module and specifically, whether the group task and regular contact with students enhanced their engagement in the module. The lessons learnt from these reflections could be used not only to improve my practice within the Acc12 module for future intakes but also to improve the other modules in the degree which are still in the process of being developed. The ultimate objective, however, is to improve the experience of the students (Hazelton and Haigh 2010; Helfaya 2019).

Action research has certain limitations as noted by Gibbs et al. (2017) in their literature review of action research in higher education. They mention that this type of research is often performed with a single cohort by an insider-researcher, which makes it difficult to compare and generalise the findings. Moreover, it relies on reflection by students and the researcher and it lacks consideration of ethical issues. In this study, I did not try to eliminate these limitations as they are part of what makes action research a unique research method. I did enhance the personal reflections and perspectives of students with descriptive and correlation analysis of the activity and student performance within the LMS. Ethical clearance was received by the university committee to conduct the research in the appropriate manner.

This article reflects only on the first cycle of the action research process. Thus the steps which are followed include planning for engagement to occur, taking action through implementation of the group task, observing the online participation within the LMS and reflecting on the student perspectives as well as self-reflection by the researcher.

\section{PLANNING: THE FIVE ELEMENTS OF ENGAGEMENT}

I purposefully planned for engagement to occur in the Acc12 module by incorporating the five elements of engagement in the following way: 
Table 2: Online engagement in the Acc12 module

\begin{tabular}{|c|c|}
\hline Type of engagement & Incorporation in the Acc12 module \\
\hline Social engagement & $\begin{array}{l}\text { - I developed an introductory discussion board where all students could } \\
\text { introduce themselves to the "class"; } \\
\text { - I created discussion boards for every unit where academic and administrative } \\
\text { queries could be asked and answered by fellow students and myself as the } \\
\text { module coordinator; } \\
\text { - I also created a separate discussion board for every group so that they could } \\
\text { freely discuss the group task without the other groups having insight into their } \\
\text { discussions; } \\
\text { - Students were encouraged to interact with their group by using other social } \\
\text { networks such as WhatsApp. }\end{array}$ \\
\hline Cognitive engagement & $\begin{array}{l}\text { - The group task was structured in such a way that students had to socially } \\
\text { construct knowledge on a specific topic within the accounting module; } \\
\text { - The students had to gain this knowledge through their prescribed textbook or } \\
\text { by using other reputable sources; } \\
\text { - Their understanding of the content was then presented in a video; part of their } \\
\text { understanding was to link their meaning to the accounting process of } \\
\text { identification, measurement, recognition, presentation and disclosure. }\end{array}$ \\
\hline Behavioural engagement & $\begin{array}{l}\text { - I encouraged all students from the first week of the module to work } \\
\text { consistently and to participate in all the online activities; } \\
\text { - I further reviewed the activity logs within the LMS regularly and on a Thursday } \\
\text { encouraged those who were not active (through a personal email) to start with } \\
\text { the week's work; } \\
\text { - I created regular announcements and sent email reminders to communicate } \\
\text { and engage with the students. }\end{array}$ \\
\hline Collaborative engagement & $\begin{array}{l}\text { - I reminded the students that one of the exit level outcomes of the degree is to } \\
\text { work within a team; } \\
\text { - The groups for the group task were kept fairly small and therefore all group } \\
\text { members had to participate to create a successful video; } \\
\text { - I encouraged the members of the group to stay positive, to participate fully in } \\
\text { the group task and to enjoy the process. }\end{array}$ \\
\hline Emotional engagement & $\begin{array}{l}\text { - I dealt with the emotional process of learning by regularly looking into the } \\
\text { discussion board posts as well as emails from students to see if there was } \\
\text { still interest in the module and to deal with any issues that may cause anxiety; } \\
\text { The group task required students to be emotionally present to their peers and } \\
\text { to commit to the task for it to be a success. }\end{array}$ \\
\hline
\end{tabular}

\section{TAKING ACTION: THE GROUP TASK}

In the Acc12 module, the students were required to complete a group video assignment. They were randomly placed in groups through the LMS and were required to investigate a specific liability from the four that are covered in the syllabus, namely, bank and supplier's loans, lease liabilities, provisions and contingent liabilities. Students had to interact with each other remotely so that a video could be created collaboratively on their specific liability.

The video could be made using any software available, had to be between 5 to 15 minutes long and had to clearly provide information on the identification, recognition, measurement, presentation and disclosure of the specific liability. Students were referred to the textbook that provides insight into the four liabilities, but no other content was provided. The group therefore had to read the textbook (or any other resource) to gain knowledge of their specific liability.

In Week 2 of the module, ten groups were created with four members in each group (except for one group that only had three members). The deadline for the assignment was the 
end of Week 5, giving students four weeks to collaborate and complete the assignment. I marked the group video assignment and a group mark was assigned which counted 20 per cent towards their final module mark.

\section{OBSERVING: ONLINE PARTICIPATION AND ENGAGEMENT}

I observed the behavioural engagement of the 39 students enrolled for the Acc12 module in May 2019 through their participation in the online elements of the module. In order to fully understand their online behaviour, a descriptive and correlation analysis was performed on the two previous modules that the students were exposed to, namely, Accounting 11 (Acc11) and Principles of Business 11 (PoB11). The following observations could be made from the Course Activity Overview report as well as the Grade Centre ${ }^{4}$ from those two modules.

\section{Descriptive and correlation analysis}

The descriptive statistics of the Acc11 and PoB11 modules are shown in Table 3. The minimum scores of zero and the low average scores indicate that there were a number of students in these two modules who did not engage at all in the module and who ultimately did not pass the module. The inverse must also be noted insofar as there were a number of students who were highly active and engaged. What was further interesting to note from the previous two modules was that in the Acc11 module, most of the time was spent by students on a Sunday, while for PoB11 it was on a Wednesday, due to a mid-week deadline on the discussion posts for that module.

Table 3: Descriptive statistics

\begin{tabular}{|c|c|c|c|c|c|}
\hline Description & Minimum & Maximum & Mean & Median & Std. deviation \\
\hline Total hours for Acc11 & 0.00 & 250.92 & 40.23 & 30.04 & 40.19 \\
\hline Total grade for Acc11 & 0.00 & 86.00 & 42.89 & 50.00 & 28.19 \\
\hline Total hours for PoB11 & 0.00 & 84.84 & 34.95 & 37.30 & 25.21 \\
\hline Total grade for PoB11 & 0.00 & 80.00 & 45.23 & 58.50 & 30.52 \\
\hline
\end{tabular}

A t-statistic probability test was performed to determine the correlation between the hours spent and the marks obtained for the two modules. It was found that for Acc11, a positive moderate $(\mathrm{r}=0.52)$ and significant $(\mathrm{t}>2(4.15)$ and $\mathrm{p}<0.05(0.0001))$ correlation exists between hours spent and the mark that the student obtained. For the PoB11 module, a very high positive correlation $(\mathrm{r}=0.81)$ and highly significant $(\mathrm{t}>2(6.26)$ and $\mathrm{p}<0.05(0.0000))$ correlation exists between hours spent and the mark obtained. The reason for this high correlation could be that in the PoB11 module, students were required to make weekly discussion board posts based on their 
knowledge of the week's content; they also had to respond to their fellow students' posts. They therefore had to spend a considerable amount of time within the LMS. Their time was rewarded with the marks that they obtained for the discussion posts.

\section{Behavioral engagement in Acc12}

With the knowledge from the two previous modules of there being a significant relationship between the time that students spend on a module and their success in the module, it was noted that by the Thursday of Week 1 of the Acc12 module, 13 students were inactive in the module (spending less than an hour at that stage). I knew from the experience of the previous modules, that some might only start with the content over the weekend. Nonetheless, a reminder email was sent to those 13 students. Of those 13 students, eight responded to the email and asked for an extension for the Week 1 deadlines. The five remaining students did not respond to the email.

Unfortunately, the five inactive students from Week 1 continued to be inactive throughout the module and any communication with them was not responded to. Over the next few weeks, three more students became inactive. One student indicated in Week 5 that due to unforeseen circumstances she could no longer continue with the module. Up until that time, there were no signs of inactivity and she was one of the top students. One student decided not to participate in the group assignment and I was only made aware of this non-participation once the group assignment had been handed in for marking. The third student failed to complete any of the weekly assignments. I communicated with him regularly and extended the deadlines for several of the weeks, but he still failed to complete the weekly assignments.

If I compare the results of Acc12 to Acc11 and PoB11 (refer Tables 5 and 6) and analyse the differences through a ANOVA F-Test, it can be noted that there is a significant statistical difference between the average marks of the three modules $(F(2,107)=3.293, p=0.041)$, with Acc12 showing the highest average marks. The average hours spent within the three modules are, however, statistically the same $(F(2,107=0.5017, \mathrm{p}=0.607))$.

Table 5: Comparison of average marks

\begin{tabular}{|c|c|c|c|c|}
\hline Variable & Count & Mean & Std. Deviation & Std. Error of Mean \\
\hline Acc11 marks & 49 & 42.89796 & 28.19297 & 4.027567 \\
\hline PoB11 marks & 22 & 45.22727 & 30.52233 & 6.507382 \\
\hline Acc12 marks & 39 & 57.10256 & 21.74468 & 3.481936 \\
\hline
\end{tabular}

These results could indicate that even though the increased encouragement to interact and engage within the Acc12 module did not increase the average time that students spent within the module, it did cause more students to engage and therefore the average mark increased. A 
significant part of the Acc12 module was the group task that was mostly completed away from the LMS, further increasing the significance of these results. Consequently, 79 per cent of the cohort passed Acc12 (compared to 51\% in Acc11 and 64\% in PoB11).

Table 6: Comparison of average hours

\begin{tabular}{|c|c|c|c|c|}
\hline Variable & Count & Mean & Std. Deviation & Std. Error of Mean \\
\hline Acc11 hours & 49 & 40.23408 & 40.19494 & 5.742134 \\
\hline PoB11 hours & 22 & 34.95227 & 25.21369 & 5.375576 \\
\hline Acc12 hours & 39 & 43.76923 & 26.19447 & 4.194472 \\
\hline
\end{tabular}

\section{REFLECTING: REFLECTIVE JOURNAL ENTRIES}

Students were asked to reflect on the video assignment through ten reflective questions which they answered in a journal tool in the LMS. As the module coordinator, I am able to access and view the private journal reflections of the students but these reflections cannot be viewed by other students. Participation in the study through answering the questions was voluntary and there was no incentive to participate. There were 27 students who answered the reflective questions. A qualitative research approach was used to gain an in-depth understanding of the students' experiences of the group assignment. Each student's answer was extracted from the LMS and, through a process of thematic content analysis, was analysed and categorised into themes (Henning, Van Rensburg and Smit 2004). Where appropriate, codes were assigned to the identified themes and categories.

\section{Communicate online: Social engagement}

All groups had an initial online meeting through the discussion board, e-mail, Skype or the Collaborate tool in Blackboard. After that, most communications were ongoing and as often as necessary through WhatsApp for all ten groups. Only one group had a very structured meeting process:

"There were 4 meetings. The first meeting was to discuss how we would go about the project. The second meeting was to collect the work that everyone did individually and assemble it. The third meeting was to plan a first draft and the final meeting was to discuss the final draft."

\section{Construction of knowledge: Cognitive engagement}

The construction or creation of knowledge on the specific liability assigned to each group occurred in one of two ways. Some groups divided their liability topic into different sections, with each member of the group researching only their part. Here is how one group described the process that they followed: 
"The requirements for the video were split into the four sections of definition, recognition, measurement and presentation and disclosure. The four group members chose their preferred sections and from there on, each group member researched their section; formulating what they perceived as the key points followed by an example to better the explanation."

The other approach was that everyone in the group had to research the liability as a whole and then it was divided into sections as preferred by each group member. The group explained this process as follows:

"We read up on it and did the necessary research to understand the liability as well as the practice questions to know how to recognize, measure, present and disclose the liability. From there we delegated the work amongst ourselves and combined, reviewed and finalized the end product."

\section{Group experience: Collaborative engagement}

From the reflections it was noted that all the groups had a good overall group experience, except for one group. In this group, one student effectively completed the video assignment on her own as her group members failed to communicate and participate. Her reflection on her group experience was as follows:

"In all honesty I cannot even answer this question because we didn't work together and in my opinion if I didn't do the work on my own there would have been no video for our group. The lack of proper communication on my group members' part was shocking."

Even though most of the groups had a good group experience, there were still challenges that had to be overcome. The importance of adhering to deadlines so that others would not be negatively affected was reiterated by this student:

"We had agreed upon deadlines within our group to ensure that things were completed timeously. Unfortunately, some group members saw only fit to submit their portions on Saturday."

Finding an available time for all group members to meet was another feature of group work that had to be navigated: "It is extremely difficult to align all the schedules of the individual members and the quality of the work is usually negatively impacted". Group work in any educational setting should simulate what students will experience in real life and part of that will require dealing with whatever issues the group might face:

"I enjoyed the group activity. It was a good real life example of how group projects goes in the real word. Not everyone will always do what is expected of them - the group has to decide which course of action to take to make sure everything is done on time." 
It was interesting to note that although there are some students who absolutely preferred working on their own, some of them realised that at times working in a group could be a beneficial learning experience:

"Personally I prefer working on my own because I work at my pace and don't have to wait for an entire group, however this time I learnt that u get more research and learn more within a group." Another student confirmed this by commenting: "I prefer self-study as it allows me to concentrate without certain constraints, however after doing the group assignment I feel both are necessary as it allows you to see and understand how different people look at the same problem."

\section{Overall experience: Emotional engagement}

From the student comments, the group task appeared to have been a positive experience, especially regarding the collaborative creation of knowledge. Not all the students, however, felt that a video assignment was the best medium to engage all the group members as creating the video was mainly left to one of the group members:

"Although all of us do have some computer skills and could produce a video, as required, it is an extremely time consuming process and not really a part of the assignment on which every member within the group can work." Another student conveyed her anxiousness with the video creation process: “... and consequently editing and uploading was left to me regardless of what was priorly agreed upon. The work ended up not being divided equally, and was completed under immense pressure.”

One student provided an appropriate summary of what group work in an online setting requires:

"Group work in this medium relies heavily on trust - trusting that each member of the group will bring about their contribution to the assignment - and trust that the work that each member contributes will be on a standard that is acceptable to all the members within the group."

\section{REFLECTING: SELF-REFLECTION BY THE RESEARCHER}

My observations of the students' participation within the LMS and review of their reflections revealed the following:

- It was encouraging to note that inactive students within the first week responded positively to an email that I sent to urge them to become active in the module. Although adhering to deadlines and the skill of time management is important to instill in students, adjusting those deadlines at times motivates students to continue with their studies.

- It was disappointing to see that no matter how many motivating emails I sent, that some students did not participate in the activities of the module and will ultimately be unsuccessful in passing the module. This may be because they lack self-regulatory skills 
or that the demands of work and family could not be reconciled with the requirements of the module.

- From the student reflections, I noted that the group task was a positive experience for most students, with the exception of one of the groups. Even students who preferred working on their own acknowledged the benefit of working collaboratively within a group.

- I noticed that the students particularly enjoyed the social aspect of completing the assignment tasks. Several positive comments were made reflecting how they had learned from each other and respected the different views of their peers.

- An unintended consequence of requiring the assignment to be submitted in video format was that, because of their geographic dispersion, only one group member at a time could work on creating and editing the video. Even though the assignment was intended to encourage group work, the opposite occurred in the final stages of the assignment.

- Having to create the video also caused undue pressure and anxiety for the responsible group member; moreover, none of the students could see the skill of video-making featuring prominently in their future careers.

\section{DISCUSSION: IMPLICATIONS, LIMITATIONS AND FUTURE RESEARCH}

This study showed that student engagement in online learning is very important. This is because online learners do not have any physical engagement with the institution. It is therefore essential to create numerous opportunities for them to engage online. In this study, I have used the online engagement framework proposed by Redmond et al. (2018) to purposefully create a course where the five elements were included in the design of the course. It was, however, observed in this study that even intentionally created opportunities to engage might not be taken up by students as their engagement in the module first requires them to make the decision to actually engage. It could also show that there are many factors influencing a student's engagement and not all can be controlled by the educator (Kahu 2013).

There is agreement in literature that sending regular announcements or email reminders is an important engagement strategy (Martin and Bolliger 2018) and continuous prompting throughout a module will lead to improvements in self-regulation, learning and retention (Wandler and Imbriale 2017). However, not all students desire connection with the instructor or other learners and some might not respond to any engagement activities (Schroeder et al. 2016). Where student numbers are small, educators can get to know their students and will therefore sense when to prod and remind and when to pull back.

Within the social constructivist view of learning, creating knowledge collaboratively will 
always be a powerful way for students to learn. In this study, students had to gain knowledge of a liability within a group. From their reflections it was noted that they enjoyed this part of the assignment. They learned from each other and respected the different views of their peers. Stanley and Zhang (2018) noted that video production can enhance learning, however, this was not the case in this study. In future, it would be better to change that part of the assignment to either require all members to submit a part of a video or to change the format completely to a written assignment.

This study reported on the first cycle in an action research enquiry. When the Acc12 module is presented again, I will continue to observe students through the LMS and prompt them, especially in the first week, to become active. It might also be beneficial to send students their individual activity reports and the module statistics, as shown in this article, as they may be more persuaded by statistical data. The group task will also be changed to a combined written assignment, in place of a video assignment. I believe that it is truly important for students to navigate through working within a group as this is a task that the students will encounter in their professional careers. The creation of the video appears to have been more of a distraction rather than a learning opportunity and therefore that part of the assignment will be amended.

This study has certain limitations. It reflects on a small number of students within one module of an online degree for one cycle within the action research methodology and therefore the generalisability of the results is limited. However, the purpose of action research is not necessarily to generalise but rather, to learn from the experience, which could then be used in other educational settings. The action research cycle will be repeated for the next Acc12 intake with the suggested changes in place.

This study contributes to existing literature by reflecting on the importance of student engagement in an online accounting module and how this activity can be incorporated by using an engagement framework. Future research could expand the study to other modules within the degree and even to other online degrees so that educators can have a practical plan of how to provide opportunities for proper engagement for students within an online learning environment and ultimately, for the students to succeed in their online studies.

\section{NOTES}

1. The LMS is the software application used to deliver online courses. It provides the learning interface where resources for each module are uploaded in a structured manner. The LMS used by UJ is Blackboard Learn.

2. A module is a self-contained course that covers a subject (such as Financial Accounting, Financial Management, Principles of Business etc.). It is assessed independently from other modules. Every module in the online accounting degree is facilitated by a module coordinator, the educator or lecturer. The online module is divided into seven units over seven weeks, with a unit starting on 
the Monday of a specific week. All activities for a unit must be completed by the Sunday of the week at 23:59 (CAT).

3. Several course reports can be extracted from Blackboard to analyse student activity. Reports such as the Overall Summary of User Activity displays user activity for all areas of the course, as well as activity dates, times and days of the week. Single Overview for Single Course displays an individual student's activity within a course, sorted by date. The report mostly used for this study was the Course Activity Overview Report which displays overall activity in a course, sorted by student. It can be filtered for a specific time period and includes data on the total and average time spent per student and the type of activity each student had in the course.

4. For every assessment or assignment created in Blackboard, a mark is given that will be reflected in the Grade Centre. The Grade Centre provides a summary of all the marks per student for all the assessments and assignments. When no mark occurs, it can be safely assumed that the student did not complete that activity or assignment.

\section{REFERENCES}

Africacheck. 2018. Funding and the changing face of South Africa's public universities. https://africacheck.org/factsheets/factsheet-funding-changing-face-sas-public-universities/ (Accessed 16 January 2019).

Artino Jr., A. R. and J. M. Stephens. 2009. Academic motivation and self-regulation: A comparative analysis of undergraduate and graduate students learning online. Internet and Higher Education 12: 146-151. doi: 10.1016/j.iheduc.2009.02.001.

Astin, A. W. 1984. Student involvement: A developmental theory for higher education. Journal of College Student Development 25: 297-308.

Bali, S. and M. C. Liu. 2018. Students' perceptions toward online learning and face-to-face learning course. Journal of Physics: Conference Series 1108. doi: 10.1088/1742-6596/1108/1/012094.

Barnard, L., W. Y. Lan, Y. M. To, V. O. Paton and S. Lai. 2009. Measuring self-regulation in online and blended learning environments. Internet and Higher Education 12: 1-6. doi: 10.1016/j.iheduc.2008.10.005.

Burch, G. F., N. A. Heller, J. J. Burch, R. Freed and S. A. Steed. 2015. Student engagement: Developing a conceptual framework and survey instrument. Journal of Education for Business 90: 224-229.

BusinessTech. 2017. The most popular fields of study in South Africa. https://businesstech.co.za/ news/business/155537/the-most-popular-fields-of-study-in-south-africa/ (Accessed 16 January 2019).

Canal, L., P. Ghislandi and R. Micciolo. 2015. Pattern of accesses over time in an online asynchronous forum and academic achievements. British Journal of Educational Technology 46(3): 619-628. doi: $10.111 /$ bjet.12158.

Carr-Chellman, A. and P. Duchastel. 2000. The ideal online course. British Journal of Educational Technology 31(3): 229-241.

Carver, L. B., K. Mukherjee and R. Lucio. 2017. Relationship between grades earned and time in online courses. Online Learning Journal 21(4): 303-313.

Cho, M. and B. J. Kim. 2013. Students' self-regulation for interaction with others in online learning environment. Internet and Higher Education 17: 69-75. http://dx.doi.org/10.1016/ j.iheduc.2012.11.001

Cho, M., Y. Kim and D. Choi. 2017. The effect of self-regulated learning on college students' perceptions of community of inquiry and affective outcomes in online learning. Internet and Higher Education 34: 10-17. http://dx.doi.org/10.1016.j.iheduc.2017.04.001

Cousin, G. 2009. Researching learning in higher education. New York and London: Routledge Taylor and Francis Group.

Cunningham, B. M. 2008. Using action research to improve learning and the classroom learning 
environment. Issues in Accounting Education 23(1): 1-30.

Curtis, S. M. 2017. Pathway to reform: Developing action research capacity in accounting education. Issues in Accounting Education 32(3): 51-79. doi: 10.2308/iace-51586.

Dani, S., M. Singhai and A. M. Hyde. 2018. Factors affecting students' perception of online learning: An empirical analysis. The Indian Journal of Industrial Relations 5(2): 334-346.

Davies, J. and M. Graff. 2005. Performance in e-learning: Online participation and student grades. British Journal of Educational Technology 36(4): 657-663.

Delen, E. and J. Liew. 2016. The use of interactive environments to promote self-regulation in online learning: A literature review. European Journal of Contemporary Education 15(1): 24-33.

Duncan, K., A. Kenworthy and R. McNamara. 2012. The effect of synchronous and asynchronous participation on students' performance in online accounting courses. Accounting Education 21(4): 431-449. doi: 10.1080/09639284.2012.673387.

Fajardo, C. 2014. Best practices for teaching accounting courses online. Journal of Business and Educational Leadership 5(1): 28-38.

Gibbs, P., P. Cartney, K. Wilkinson, J. Parkinson, S. Cunningham, C. James-Reynolds, T. Zoubir, V. Brown, P. Barter, P. Sumner, A. MacDonald, A. Dayananda and A. Pitt. 2017. Literature review on the use of action research in higher education. Educational Action Research 25(1): 3-22. doi: 10.1080/09650792.2015.1124046.

Hazelton, J. and M. Haigh. 2010. Incorporating sustainability into accounting curricula: Lessons learnt from an action research study. Accounting Education: An International Journal 19(1-2): 159178. doi: 10.1080/09639280802044451.

Helfaya, A. 2019. Assessing the use of computer-based assessment-feedback in teaching digital accountants. Accounting Education 28(1): 69-99. doi: 10.1080/09639284.2018.1501716.

Henning, E., W. van Rensburg and B. Smit. 2004. Finding your way in qualitative research. Pretoria: Van Schaik Publishers.

Hrastinski, S. 2009. A theory of online learning as online participation. Computers \& Education 52: 7882. doi: 10.1016/j.compedu.2008.06.009.

Holzweiss, P. C., S. A. Joyner, M. B. Fuller, S. Henderson and B. Young. 2014. Online graduate students' perceptions of best learning experiences. Distance Education 35(3): 311-323. doi: 10.1080/01587919.2015.955262.

Ingersoll Abbott, J. and B. R. Palatnik. 2018. Students' perceptions of their first accounting class: Implications for instructors. Accounting Education 27(1): 72-93. doi: 10.1080/ 09639284.2017.1381032.

Kahn, W. A. 1990. Psychological conditions of personal engagement and disengagement at work. Academy of Management Journal 33: 692-724.

Kahu, E. R. 2013. Framing student engagement in higher education. Studies in Higher Education 38(5): $758-773$.

Karodia, Y. 2019. Biztrends 2019: Top 11 trends in South African education. https://www. bizcommunity.com/Article/196/722/185945.html (Accessed 9 September 2019).

Kember, D. and L. Gow. 1992. Action research as a form of staff development in higher education. Higher Education 23: 297-310.

Malan, M. and N. Stegmann. 2018. Accounting students' experiences of peer assessment: A tool to develop lifelong learning. South African Journal of Accounting Research 32(2-3): 205-224.

Martin, F. and D. U. Bolliger. 2018. Engagement matters: Student perceptions on the importance of engagement strategies in the online learning environment. Online Learning Journal 22(1): 205222. doi: 10.24059/olj.v22il.1092.

Mashile, E. O. and F. J. Pretorius. 2003. Challenges of online education in a developing country. South African Journal of Higher Education 17(1): 132-139. 
McGowan, S. 2012. Going beyond the numbers in teaching financial accounting: The newsletter as an assignment option. Issues in Accounting Education 27(4): 1095-1117. doi: 10.2308/iace-50207.

Moore, M. J. 1993. Three types of interaction. In Distance education theory, ed. K. Harry, M. John and D. Keegan, 19-24. New York: Routledge.

Paisey, C. and N. J. Paisey. 2005. Improving accounting education through the use of action research. Journal of Accounting Education 23(1): 1-19.

Potter, B. N. and C. G. Johnston. 2006. The effect of interactive on-line learning systems on student learning outcomes in accounting. Journal of Accounting Education 24: 16-34.

Redmond, P., A. Heffernan, L. Abawi, A. Brown and R. Henderson. 2018. An online engagement framework for higher education. Online Learning 22(1): 183-204. doi: 10.24059/olj.v22i1.1175.

Schroeder, S., M. Baker, K. Terras, P. Mahar and K. Chiasson. 2016. Students' desired and experienced levels of connectivity to an asynchronous, online, distance degree program. Online Learning Journal 20(3): 244-263.

Stanley, D. and Y. Zhang. 2018. Student-produced videos can enhance engagement and learning in the online learning. Online Learning Journal 22(2): 5-26. doi: 10.24059/olj.v22i2.1367.

Stark, E. 2019. Examining the role of motivation and learning strategies in student success in online versus face-to-face courses. Online Learning 23(3): 234-251. doi:10.24059/olj.v23i3.1556.

Tayebinik, M. and M. Puteh. 2013. Does greater participation in online courses lead to passing grade? An EFL learning context. British Journal of Educational Technology 44(6): 199-202. doi: 10.1111/bjet.12095.

UJ see University of Johannesburg.

University of Johannesburg. 2019. Online programmes offered by UJ. https://online.uj.ac.za/ (Accessed 22 January 2019).

Van Oordt, T. and I. Mulder. 2016. Implementing basic e-learning tools into an undergraduate taxation curriculum. Meditari Accountancy Research 24(3): 341-361. https://doi.org/10.1108/MEDAR08-2015-0054

Wandler, J. and W. Imbriale. 2017. Promoting undergraduate student self-regulation in online learning environments. Online Learning Journal 21(2). doi: 10.24059/olj.v2li2.881.

Wells, P., P. de Lange and P. Fieger. 2008. Integrating a virtual learning environment into a second-year accounting course: Determinants of overall student perception. Accounting \& Finance 48: 503518. doi: 10.1111/j.1467-629x.2007.00249.x.

Williams, B., C. Horner, and S. Allen. 2019. Flipped vs traditional teaching perspectives in a first year accounting unit: An action research study. Accounting Education 28(4): 333-352. doi: 10.1080/09639284.2019.1609536.

Zeng, B. and M. Warschauer. 2015. Participation, interaction, and academic achievement in an online discussion environment. Computers \& Education 84: 78-89. http://dx.doi.org/10.1016/j/ compedu. 2015.01 .008

Zimmerman, B. J. and D. H. Schunk. 2001. Self-regulated learning and academic achievement: Theoretical perspectives. $2^{\text {nd }}$ Edition. Mahwah, NJ: Lawrence Erlbaum Associates. 